\title{
Coherence and Dissonance: A New Understanding in Management and Organizations
}

\author{
Fernando Toro-Alvarez \\ Organizational Behavior Research Center Cincel, Medellín, Colombia \\ Email: ftoro@cincel.com.co
}

How to cite this paper: Toro-Alvarez, F. (2020). Coherence and Dissonance: A New Understanding in Management and Organizations. Psychology, 11, 748-762. https://doi.org/10.4236/psych.2020.115051

Received: April 19, 2020

Accepted: May 26, 2020

Published: May 29, 2020

Copyright $\odot 2020$ by author(s) and Scientific Research Publishing Inc. This work is licensed under the Creative Commons Attribution International License (CC BY 4.0).

http://creativecommons.org/licenses/by/4.0/

\section{(c) (i) Open Access}

\begin{abstract}
This paper argues that coherence is something about which cognitive dissonance theory is concerned but not explored. After examining the meaning of coherence in several disciplines in psychology, this writing introduces the concept of Coherence Judgment. The author argues that cognitive dissonance motivates the search for coherence, as a means to get rid of dissonance. Coherence judgment, as a particular cognitive process, allows the subject to decide about the way to reduce or remove dissonance, and then to verify the effect achieved. On the other hand, incoherence may trigger dissonance, which in turn motivates the search for coherence. After putting forward a formal definition of Coherence Judgment, the author argues whether coherence is a feature of reality, as some authors propose, or mainly a cognitive process, and also whether psychology needs a coherence Judgment concept. Several implications are outlined for theory development and useful applications in management and organizational design and change.
\end{abstract}

\section{Keywords}

Coherence, Coherence Judgment, Cognitive Dissonance, Management, Organizational Change

\section{Introduction}

Coherence deserves consideration in psychology because a formal conceptualization and theorizing are lacking, even though several authors refer to it as part of their reasoning or explanations. There is an evidently scarce consensus about its meaning. Different researchers in psychology support some theoretical explanations appealing to concepts of incoherence, discrepancy, inconsistency, or 
dissonance (Swann, 1983; Higgins, 1987; Swann, Griffin, Predmore, \& Gaines, 1987; Higgins 1987). Everyone uses it without a theoretical background providing meaning and scope. Organizational studies based on different conceptual perspectives also use the term coherence with a weak agreement in its meaning (Garcia \& Ruiz, 2007; Ramos \& Jordao, 2013; Heggena \& Terumb, 2013). In an applied perspective, coherence is a necessary concept in management, organizational design, organizational change, policymaking, and even leadership and human resources. For instance, coherence has been found related to several criteria of success in organizations such as between technology and objectives (Crettenand, Laperrousa, Finger, \& Duthaler, 2010), between strategy and structure (Garcia \& Ruiz, 2007) or between abilities and market strategy (Leindwan \& Mainardi, 2010). Many facts and effects are needing this type of concept for better understanding, explanation, and decision making.

One common criticism of organizational behavior studies is the proliferation of constructs, theories, and models that remain disconnected from one another, mainly missing the development of central unifying theories that allow for a better understanding of human behavior at work (Kim, Ployhart, \& Gibson, 2018). The current paper argues, agreeing with this point of view, that coherence may be seen as a concept related to cognitive dissonance theory (CDT), although not considered and explained in that theoretical context. Coherence may be a relevant psychological construct that compliments and expands cognitive theorizing.

\section{Main Frame in Cognitive Dissonance Theory}

Festinger views dissonance as "[...] two cognitions inconsistent with each other ... Cognitions refer to knowledge, opinions, and beliefs about oneself and one's environment ... Cognitive dissonance is an antecedent condition that leads to activity toward dissonance reduction" (Festinger, 1957: p. 3). These statements allow us to lay down the significance and scope that Festinger attributes to his construct of dissonance. When there is no misfit between cognitive elements, a state of consonance ensues, something that seems to lack interest in the comprehension and dynamics of dissonance. His principal focus of interest is the motivational effect of dissonance, but not dissonance itself. Strictly speaking, the central elements of dissonance construct are a state of discomfort emerging from inconsistency and its motivational effect, which promotes the search for coherence. Cognitive dissonance may be considered, therefore, as a way of referring to incoherence. Although Festinger seems to be more interested in its effects, his theoretic proposal shows that cognitive dissonance is something that people confront in their daily life, with significant psychological and behavioral effects.

Although dissonance theory remains relatively unchanged despite abundant revisions (Beauvois \& Joule, 2019), some new concepts such as the Meaning Maintenance Model offers a theoretical expansion (Randles, Inzlich, Prolux, Tullett, \& Heine, 2015). In this approach, the aversive arousal induced by dis- 
sonance motivates the individual to address the violation in at least two ways: Support, affirming commitment to an accessible belief that makes sense to the situation (Heine \& Lehman, 1997; Heine et al. 2006), which means achieving coherence; Abstraction, being motivated to look for and learn a new meaning or frame of reference (Prolux, Heine, \& Vohs, 2010; Proulx \& Inzlicht, 2012), again to achieve coherence, processes considered as fluid compensation (Randles, Inzlich, Prolux, Tullett, \& Heine, 2015). Dissonance is reduced or eliminated through support or abstraction, finding this way some kind of coherence.

Another theoretic approach related to dissonance is the concept of Sensemaking. It refers to a process through which people try to understand novel, confused, mistaken or ambiguous events and it is activated by facts that confront expectancies (Weick, Sutcliffe, \& Obstfeld, 2005; Maitlis \& Christianson, 2014), in order to find some meaning that can guide subsequent decisions or behaviors (Brown, Corville \& Pye, 2015). Mistaken or confusing situations represent a misfit between events and expectancies conveying, according to theory, to a search for fit or coherence.

Other studies following the cognitive dissonance model were performed to explain and manage different inconsistencies, such as between self and social reality (Swann \& Read, 1981; Swann, 1983) or between self domains that trigger adverse emotional reactions (Higgins, 1987). They have in common that perceived inconsistencies lead to the judgment and feeling of dissonance, an aversive condition that produces arousal. The arousal motivates thinking or behavior addressed to resolving in some way the inconsistency, which means searching for coherence. Coherence and incoherence are both related in that theoretical context.

Instead of considering those approaches as different theories, it would be convenient and parsimonious, as proposed here, to take them as diverse elements contributing to a broad, strong, and including theory. Consistent with this reasoning, we will explore in the next section key relations between dissonance and coherence.

\section{How Are Dissonance and Coherence Related?}

Dissonance Motivates the Search for Coherence. This hypothesis asserts that the arousal produced by dissonance may motivate different reactions addressed to gain consonance or coherence. Then, coherence is the main effect achieved by dissonance and not merely a reduction or elimination of tension or discomfort. The concepts in the Meaning Maintenance Model and Sensemaking both outline the same as Festinger's theory: avoiding the undesirable or aversive cognitive dissonance. Why is avoidance necessary? Because coherence is a condition without contradiction or inconsistency, in which there is not aversive arousal but feelings of harmony (McCraty \& Childre, 2002; McCraty 2011), consistency (Gruber, Mauss, \& Tamir, 2011; Bullis, Bøe, Asnaani, \& Hofmann, 2014) or logic (Olsson, 2014; Hecker, Hahn, \& Rollings, 2016). In this context, it is feasible to 
conclude that dissonance, and its aversive arousal, motivates the search for coherence, which may be understood as a kind of ideal state in which people experience consistency, harmony, and lack of dissonance. Of course, there should be different ways of achieving coherence in order to avoid dissonance or to recover cognitive and emotional consistency.

Coherence seems to be an ideal cognitive state, experienced as necessary as dissonance becomes disturbing. Then, dissonance promotes action and reaction intended to gain a more pleasant and consistent state of coherence. The explanation lacking in the current theorizing in CDT is that a search for coherence is motivated when dissonance and its aversive effect appear. In this context, it is necessary to ask if coherence is the opposite of dissonance, or they are different constructs with some interdependence. An adequate answer needs consideration.

Reasons argued in this writing, and the lack of other convincing facts suggest that a search for coherence is motivated by dissonance, mainly because of its aversive effect, more emotional than cognitive, as proposed by Higgins (1987) and Swann (1983). Accordingly, a search for coherence may be understood as a reaction to dissonance, but there is no available evidence that this is its exclusive effect. People may have coherent thoughts without previous dissonance, as in the case of planning a trip, creating a business, giving advice to somebody else, or writing a letter, and if this is the case, thinking coherently and feeling coherence are not exclusive effects of dissonance. Such effects may be a consequence of other conditions like free-thinking, expectations, contextual demands, or positive feelings. It may occur independently, such as in the case of associative processes and propositional thought (Gawronski \& Strack, 2004; Sperber, 2005; Mercier, 2012) and even may serve as a means of cognitive regulation (Toro, 2018).

\section{Is Coherence a Feature of Reality or a Cognitive Process?}

In the case of being a feature of reality, a psychological explanation was unnecessary, but convenient if it is a cognitive process. Some authors and researchers assert that any reality may be coherent or incoherent in-it-self, independently of human judgment. Schubert and Olsson $(2012,2013)$ suggest that coherence can be understood in several ways: 1 ) as the degree of consistency between different elements of a set; 2) as a particular agreement between critical elements of a set; 3 ) as the degree of mutual support between elements of a set. In a similar vein, León (2009) understands coherence as a characteristic of any social or labor reality, in which it is possible to observe a systemic convergence and interdependence among facts or realities, whose coincidence affords order, integrates, coordinates, harmonizes and allows predictions. In the context of organizational analysis, Garcia and Ruiz (2007) examined the coherence in companies of electronics and communications and found a relationship between positive or negative results and the degree of coherence between structure, processes, and strate- 
gies. Approaches like those argue that coherence may be a feature aspect inherent to any reality, with positive effects, in the case of being present.

Other studies argue that coherence is not an aspect of reality but a pattern of thinking that enables people to integrate scattered facts or data to assign meaning and sense, as a condition to behave. Studies in Self-consistency have considered it as a self-directed mechanism integrating different elements of the experience, whose final effect is to maintain personality's unity and organization (Morse \& Gergen, 1970; Swann, Griffin, Predmore, \& Gaines, 1987; Swann, 1983). The idea of Self-directed mechanisms refers to cognitive, emotional, and behavioral processes that enable people to interpret their experience in such a way that it is possible to develop an integrated view of themselves. In a different perspective, Mercier (2012) theorized about two forms of coherence in the human cognitive system. System 1 is a regulation mechanism that assures coherence between different representations, is heuristic, quick, and unconscious. Maintains consistency among emotions, intuitions, and beliefs, and is persistent over time. Here, coherence has a regulatory role, which may determine what principles, beliefs, or behaviors to maintain or discard. System 2 is slow, conscious, requires effort, and may correct errors emerging from System 1. It is associated with the consistency of reasoning and planning. It evaluates the coherence of various systems of thought (beliefs, values, principles of behavior), and makes decisions and inferences. In recent writings, the current author has developed theorizing around the concept of coherence as a subjective cognitive process related to the functions of cognitive and emotional regulation and behavioral adaptation (Toro, 2015; Toro 2018). This approach emphasizes that considering any reality as coherent is the outcome of a psychological process named Coherence Judgement. It is through this type of judgment how people decide that something is or not coherent and, because of its subjective character, the same facts may be judged coherent by someone and incoherent by somebody else.

According to the different ideas argued in this writing, a sound conclusion should consider that coherence is a subjective judgment related to the consistency of facts or information. Nonetheless, facts or data may be highly consistent but be judged subjectively as inconsistent. Inconsistent information or facts may appear consistent because some personal experience, reasoning, or attitude puts them together in a subjective interpretation. Therefore, perceived coherence may depend on the degree of data fit but also the cognitive process, so that we will examine in some detail the concept of Coherence.

\section{What Does Coherence Mean?}

After a comprehensive literature revision of the concept of coherence (Toro, 2018), which included the disciplines of epistemology, biopsychology, and psychology (cognitive, social, organizational), several studies considering related terms and concepts will be summarized hereafter. 
Some studies in epistemology consider this concept, and several tend to assert that coherence is a lack of contradiction or a degree of agreement among different elements of a set. Then coherence is mainly a feature of data that makes them credible and reliable (Harris \& Hann, 2009; Shubert \& Olsson, 2013), and then this is an issue of form and logic inherent to data or facts (Thagard, 2002, 2005). Notwithstanding, those authors also consider this kind of coherence as a criterion of truthfulness. As may be seen, credibility and truthfulness are cognitive reactions emerging from integrated sets of data or facts but not a property of those facts (Toro, 2018).

Biopsychology integrates concepts from physiology, neuroscience, and psychology. Different authors provide evidence that the experiences of a person are physiologically connected to regulatory centers of emotion and with areas in the cerebral cortex in charge of complex thought and response elicitation (McCraty, 2011; Silvers, Weber, Wager, \& Ochsner, 2015; Ajay, Satpute, Nook, Narayanan, Shu, Weber, \& Ochsner, 2016; Zaki, Kallman, Wimmer, Ochsner, \& Shohamy, 2016; Akinola, Kapadia, Lu, \& Mason, 2019). In this context, coherence is understood as a state of harmony or synchrony among systems (circulatory, endocrine, and nervous), such that people in a state of physiological harmony report psychological states of wellbeing, trust in themselves, a sensation of balance, peace and inner harmony (McCraty, Atkinson, Tomasino, \& Bradley, 2009; McCraty, 2011; Dan-Glauser \& Gross, 2013). When physiological stability is altered, adverse psychological effects appear, such as anxiety, stress, depression, and other behavioral manifestations (Gruber, Mauss, \& Tamir, 2011; Bullis, Bøe, Asnaani, \& Hofmann, 2014).

In the field of psychology, Antonovsky (1987) put forward the concept of Sense of Coherence, understood as a psychological disposition characterized by 1) confidence in that internal or external individual realities are explainable and predictable; 2) conviction about relying on resources to manage them; 3) belief in that those realities deserve attention. Coherence happens when those elements, together, lead the subject to cope with a demanding situation, and incoherence if one of them is weak or absent. Coherence is not an issue of all-or-nothing because it may be more or less intense, in which case Antonovsky uses the term of Sense of Coherence. Later on, other studies examined the construct validity of this concept and found, through confirmatory factor analysis, that its better structure is one with only one factor (Larson \& Kallenger, 1999; Klepp, Mastekaasa, Sørensen, Sandager y Kleiner, 2007) and this unique variable predicted in a similar way as the Antonovsky's original studies (Griffiths, Ryan y Foster, 2011). Several studies followed Antonosvky's concept and measurement, but there is doubt today about its validity and relevance (Griffiths, Ryan y Foster, 2011). This approach contains an attempt to understand coherence as a cognitive process.

Social Psychology seems to be the discipline that paid more attention to the idea of coherence. Self-consistency and Self-discrepancy were already mentioned as models that may be complementary and enrich the CDT. It is possible to ex- 
plain such complementarity by paying attention to the fact that human beings react to incoherence because of the unpleasant effects associated with it and look for coherence as a more pleasant and consistent state of mind. Self-consistency is a tendency to internal integration, needed to the sound unity of personality. Self-discrepancy is considered a failure in the process of integration and something prone to promote disturbing emotional effects. A step forward offered by these theories concerning cognitive dissonance is the implication that dissonance is not only a cognitive process but also an issue related to the self, including emotions, experiences, expectancies, behavior, and interactions between person and environment.

The concept of Self-verification (Swann, 1983) may be understood in this context as a pattern of behavior intended to create social conditions to avoid self-discrepancy and to ensure self-consistency. These three processes evidence a risk of dissonance, not only cognitive but also emotional, that may bother the personal wellbeing. In these three cases is present a condition that motivates the search for coherence, that is to say, the aversive state, so self-verification may help to verify coherence and to prevent dissonance. The preceding three theories, related to the self, have relevant common elements to see them as complementary to the cognitive dissonance process. The three concepts could be considered, instead of independent theories, as a set of related processes enabling the subject to identify and manage dissonance in order to experience coherence.

Nevertheless, there is not enough conceptualization of the idea of consonance or coherence, and this is our focus of interest in this writing. According to our hypothesis, coherence is the result of the process that intends to identify and reduce dissonance. The preceding analysis outlined both the need for this complementary concept and its relevance to a more inclusive cognitive theory.

Some organizational studies approach the concept of coherence. A mention to some of them allows a complimentary exploration of its meaning and relevance in this context. Garcia and Ruiz (2007) examined the relationship between coherence and organizational success in communications and electronics companies. Coherence is the degree of interrelationship between different organizational elements and an idea that gives sense to those relations. It was found that good or bad organizational results were contingent on the degree of coherence between those elements. In a different study, Ramos and Jordao (2013) explored the relationship between stress and the coherence value in public and private organizations. They found that conflict between personal and organizational values attained a positive correlation with workers' stress, but this did not happen when values were convergent, and this type of value fit was understood as coherence. Heggena and Terumb (2013) studied the coherence or degree of integration among various components of the learning experience in an educational institution, and its effects on dedication to the profession and professional identification. They found a significant correlation between coherence and the results expected. Wagter, Proper, and Witte (2012) put forward a frame of reference to evaluate and manage coherence in organizations. They understood the 
concept as the alignment of a whole of elements necessary to the organizational functioning, something that should be managed. The alignment of so many diverse elements demands the definition of a unifying element that gives support and legitimates that integration. This element is usually a core concept, perspective, or principle. Writings like the ones mentioned suggest that coherence is a kind of linkage or connection among different elements, which is propitiated by the action of an idea or concept. Coherence is necessary to the right functioning and achievement of results, is a matter of degree, and because it does not emerge spontaneously, it should be intentionally managed. According to this set of characteristics, coherence seems to be less a property of data and more a mental frame that allows particular representations or constructions of reality. In any case, it is essential to distinguish between the coherence of facts and the cognitive process. Both approaches are related and need to be analyzed to the understanding of coherence. Provided that the primary purpose of this writing is the concept of coherence in a cognitive perspective, in the next paragraphs will be explained.

\section{Why Is Needed a Coherence Judgement?}

In previous writing, Toro (2018) proposed this concept and its formal definition. He understands Coherence Judgement as a cognitive process by which is assessed the degree of articulation or bonding among different facts or data, according to an idea or principle that links them. It is also the fit between ideas or facts and a criterion or concept related to them by the person. This judgment contains an assessment of the link among such elements. It emerges from the subjective meaning assigned to the experience and has cognitive, emotional, and behavioral components. By this process, the current experience is integrated into cognitive, emotional, and behavioral imprints left by previous experiences, by expectancies, and by future interests.

The following are core characteristics of the coherent judgment concept, widely discussed elsewhere (Toro, 2015, 2018): 1) Subjectivity, concept taken from González writings (2009, 2010, 2013), who explains it in terms of subjective senses -independent and personal interpretations- and subjective configurations -integration of various subjective senses related to a particular issue. 2) Inclusion of social, historical, and cultural elements of current reality. These are contextual elements outlined by Vygotsky's writings $(1925,1927)$ about conscience. 3) Potential to give a personal sense to every experience (Vygotsky, 1927; González, 2013). 4) To keep the personal meaning of identity through integrating and preserving the different experiences of life (Swann, Griffin, Predmore, \& Gaines, 1987; Swann, 1983). 5) Ensure a perception of personal consistency and consistency of answers to environmental requests (Lieberman, 2007; Doré, Zerubavel \& Ochsner, 2015). 6) Adaptation, which means coherence between behavior and situational requirements (Bandura, 1991; Banfield, Wiland, Macrae, Mute y Heatherton, 2004).

Coherence judgments are a cognitive and subjective way to assessing if a state 
of dissonance was successfully removed o reduced, as has been proposed and explained by the theories of Meaning Maintenance Model, Fluid Compensation, Sensemaking, Self-discrepancy, Self-consistency or Self-verification. Those are ways of attaining coherence when dissonance appears. Furthermore, the cognitive process by which a person is aware of dissonance is itself a coherence judgment, which allows concluding the presence or absence of an incoherence. A cognitive dissonance process is not activated when people judge coherence between facts o data, and then the original CDT has nothing to explain. The finding that something is incoherent may activate the cognitive dissonance process and, in the end, motivate the search for a coherent arrangement. According to previous considerations, coherence judgments may avoid the occurrence of dissonance. Nevertheless, detected incoherence triggers the dissonance process, and its main effect is a search for coherence, which again is evidenced through coherence judgments. This set of ideas offers an avenue for future research intended to validate these relations but also to widen the reach of dissonance theory in several respects: 1) Dissonance is not only cognitive but also emotional and behavioral. 2) Dissonance may be managed in different ways to avoid or reduce the aversive effect, but, in any case, the result is the achievement of a state of coherence. 3) The attainment of this state of coherence is assessed through a coherence judgment. 4) A coherence judgment may inhibit the occurrence of dissonance, and one judgment of incoherence may trigger it. 5) The focal process may be understood less as one of dissonance and more as one of coherence, in so far as the needed psychological effect is a state of coherence (See Figure 1).

\section{Managerial and Organizational Implications}

Some implications and applications are outlined here, so the usefulness of this conceptual proposal can help managers and organizational designers. As various organizational studies suggest (Wagter et al., 2012; Heggena \& Terum, 2013), coherence is a favorable condition that needs management, provided that it does not arise by spontaneous generation. We argued that coherent facts or situations

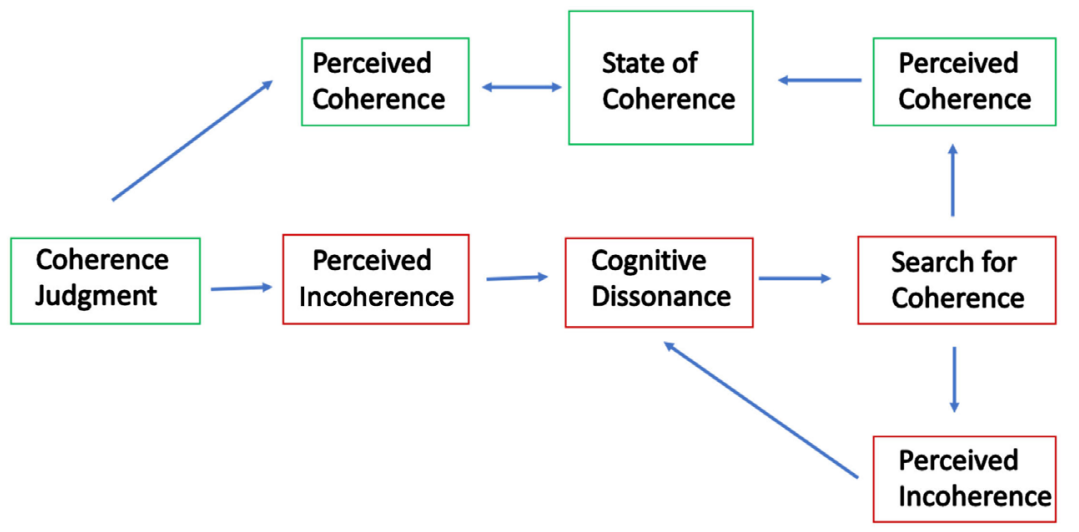

Figure 1. Relationships between coherence judgment, cognitive dissonance, and state of coherence. 
at work might be judged incoherent by some individuals. A study found, for instance, significant differences in perceptions of organizational coherence between employees according to their educational and managerial level (Toro, 2013). A different study reported that coherence between organizational policies and procedures accounted for a significant portion of the variance in a measure of quality performance in a personnel selection task (Toro, 2019)

All this implies that managers should be aware of proper coherence in their concepts, conclusions, and decisions in order to promote coherent organizational realities. However, this is not enough. Suitable strategies are also needed for people to find and understand the intended coherence. Key elements in such a strategy should consider avoidance of dissonance processes, whose prevention and solution include promoting coherence judgments (Toro, 2018). All these elements need consideration, planning, and management (Coning \& Friis, 2011).

Decision-making training activities need to develop ability and attitude for managers to understand these cognitive processes and regulate them. It is not enough to think and be coherent but also to be sure others judge such coherence. Organizational design is a crucial complex activity needing high levels of coherence (Wagter, Proper \& Witte, 2012; Galbraith, 2006). In this case, are essential: designers' coherence thinking, coherent implementation strategies, also strategies to prevent dissonance and ensure coherence judgments of people acting according to the design. In an experimental study, perceptions of coherence of a task and the subsequent coherence judgment lead participants to express positive expectancies about their job (Toro, 2018).

Change processes in organizations need a strong consideration of coherence judgments in order to prevent dissonance and avoid inconvenient emotional and cognitive effects. Several criteria suggested allow us to assess the probability that coherent adverse judgments arise from complex changes in organizations, hindering the process (Toro, 2018). It is also convenient to assess perceptions of coherence among people in different organizational sectors and concerning particular periods or circumstances. Such information allows management to monitor levels of perceived coherence and provides support for decisions or strategies concerning the effects of policies, processes, practices, or changes (Nadler, 2006). Although the author has begun to study the characteristics and effects of coherence judgments (Toro, 2015, 2018), it is clear the need to advance theoretical developments and empirical research to provide the necessary support to the new concept and theory.

\section{Conclusion}

The argument here is that coherence is a crucial concept related to de CDT and, even more, that is somehow implicit in the dissonance theorizing because perceived incoherence activates the dissonance process, and coherence inhibits it. Besides, the result of a dissonance process is the achievement of a state of coherence. In this context, coherence is something about which dissonance is con- 
cerned, but its consideration has been absent.

Instead of putting forward a new theory of cognitive consonance or coherence, the author agrees with the claim of Kim, Ployhart, and Gibson (2018) of avoiding the proliferation of concepts and theories and look for more wide, comprehensible and straightforward theoretic approaches. The current discussion allowed the opportunity of also reflecting on the fact that cognitive dissonance is a term that falls short because such dissonance may also occur between emotions, facts of reality, or even behaviors. All this means a whole enrichment of CDT and an attempt to give context to a new theory about coherence.

Coherence judgment is a cognitive process needed to understand how people decide that something is coherent or not and how are created coherent outputs such as theories, structures, plans, strategies, speeches, laws, or organized collectivities. Coherence seems to be a necessary condition for the organized collectivities to function but also for the individual wellbeing. Coherence judgment is the way by which people decide the degree of consonance or dissonance of something and a way to the understanding of individual differences when facts should be considered consistent or inconsistent.

\section{Conflicts of Interest}

The author declares no conflicts of interest regarding the publication of this paper.

\section{References}

Ajay B., Satpute, A. B., Nook, E. C., Narayanan, S., Shu, J., Weber, J., \& Ochsner, K. N. (2016). Emotions in "Black and White" or Shades of Gray? How We Think About Emotion Shapes Our Perception and Neural Representation of Emotion. Psychological Science, 27, 1428-1442. https://doi.org/10.1177/0956797616661555

Akinola, M., Kapadia, C., Lu, J. G., \& Mason, M. F. (2019). Incorporating Physiology into Creativity Research and Practice: The Effects of Bodily Stress Responses on Creativity in Organizations. Academy of Management Perspectives, 33, 163-184. https://doi.org/10.5465/amp.2017.0094

Antonovsky, A. (1987). Unraveling the Mystery of Health: How People Manage Stress and Stay Well. San Francisco, CA: Jossey-Bass.

Bandura, A. (1991). Social Cognitive Theory of Self-Regulation. Organizational Behavior and Human Decision Process, 50, 241-287. https://doi.org/10.1016/0749-5978(91)90022-L

Banfield, J. F., Wyland, C. L., Macrae, C. N., Munte, T. F., \& Heatherton, T. F. (2004). The Cognitive Neuroscience of Self-Regulation. In R. F. Baumeister, \& K. D. Vohs (Eds.), Handbook of Self-Regulation: Research, Theory, and Applications (pp. 62-83). New York: Guilford Press.

Beauvois, J.-L., \& Joule, R.-V. (2019). A Radical Point of View on Dissonance Theory. In E. Harmon-Jones (Ed.), Cognitive Dissonance: Reexamining a Pivotal Theory in Psychology (pp. 41-61). Washington DC: American Psychological Association. https://doi.org/10.1037/0000135-003

Brown, A. D., Corville, I., \& Pye, A. (2015). Making Sense of Sensemaking in Organization Studies. Organization Studies, 36, 265. https://doi.org/10.1177/0170840614559259 
Bullis, J. R., Bøe, H. J., Asnaani, A., \& Hofmann, S. G. (2014). The Benefits of Being Mindful: Trait Mindfulness Predicts Less Stress Reactivity to Suppression. Journal of Behavior Therapy and Experimental Psychiatry, 45, 57-66. https://doi.org/10.1016/j.jbtep.2013.07.006

Coning, C., \& Friis, K. (2011). Coherence and Coordination. The Limits of the Comprehensive Approach. Journal of International Peacekeeping, 15, 243-272. https://doi.org/10.1163/187541110X540553

Crettenand, N., Laperrousa, M., Finger, M., \& Duthaler, C. (2010). Performance and Coherence in Network Industries. In Third Annual Conference in Competition and Regulation in Network Industries.

Dan-Glauser, E. S., \& Gross, J. J. (2013). Emotion Regulation and Emotion Coherence: Evidence for Strategy-Specific Effects. Emotion, 13, 832-842.

https://doi.org/10.1037/a0032672

Doré, B. P., Zerubavel, N., \& Ochsner, K. N. (2015). Social Cognitive Neuroscience: A Review of Core Systems. In M. Mikulincer, \& P. R. Shaver (Eds.), APA Handbook of Personality and Social Psychology: Vol. 1. Attitudes and Social Cognition (pp. 693-720). Washington DC: American Psychological Association. https://doi.org/10.1037/14341-022

Festinger, L. (1957). An Introduction to the Theory of Dissonance. In L. Festinger (Ed.), A Theory of Cognitive Dissonance (pp. 1-30). Stanford, CA: Stanford University Press.

Galbraith, J. (2006). Matching Strategy and Structure. In J. V. Gallos (Ed.), Organization Development. San Francisco, CA: Jossey-Bass.

Garcia Villaverde, P. M., \& Ruiz Ortega, M. J. (2007). Configuraciones organizativas en sectores dinámicos y hostiles: Adecuación al contexto sectorial, coherencia interna y resultados. Cuadernos de Economía y Dirección de la Empresa, 10, 111-147. https://doi.org/10.1016/S1138-5758(07)70093-2

Gawronski, B., \& Strack, F. (2004). On the Propositional Nature of Cognitive Consistency: Dissonance Changes Explicit, But Not Implicit Attitudes. Journal of Experimental Social Psychology, 40, 535-542. https://doi.org/10.1016/j.jesp.2003.10.005

González, F. L. (2013). Subjectivity in a Historic-Cultural Perspective: Advancing over an Unfinished Legacy. Revista CS en Ciencias Sociales, 11, 19-42. https://doi.org/10.18046/recs.i11.1565

González-Rey, F. L. (2009). Epistemoligy and Ontology: A Necessary Debate to Psychology Today. Diversitas-Perspectivas en Psicología, 5, 205-224. https://doi.org/10.15332/s1794-9998.2009.0002.01

González-Rey, F. L. (2010). Sense Categories, Personal Sense, Subjective Sense in a Historic-Cultural Perspective: A Way to a Definition of Subjectivity. Universitas Psychologica, 9, 241-253. https://doi.org/10.11144/Javeriana.upsy9-1.cssp

Griffiths, C. A., Ryan, P., \& Foster, J. H. (2011). Thematic Analysis of Antonovsky's Sense of Coherence Theory. Scandinavian Journal of Psychology, 52, 168-173. https://doi.org/10.1111/j.1467-9450.2010.00838.x

Gruber, J., Mauss, I. B., \& Tamir, M. (2011). A Dark Side of Happiness? How, When, and Why Happiness Is Not Always Good. Perspectives on Psychological Science, 6, 222-233. https://doi.org/10.1177/1745691611406927

Harris, A. J. L., \& Hahn, U. (2009). Bayesian Rationality in Evaluating Multiple Testimonies: Incorporating the Role of Coherence. Journal of Experimental Psychology, Learning, Memory, and Cognition, 35, 1366-1373. https://doi.org/10.1037/a0016567

Heggena, K., \& Terum, L. I. (2013). Coherence in Professional Education: Does It Foster 
Dedication and Identification? Teaching in Higher Education, 18, 656-669. https://doi.org/10.1080/13562517.2013.774352

Heine, S. J., \& Lehman, D. R. (1997). Culture, Dissonance, and Self-Affirmation. Personality and Social Psychology Bulletin, 23, 389-400. https://doi.org/10.1177/0146167297234005

Heine, S. J., Proulx, T., \& Vohs, K. D. (2006). The Meaning Maintenance Model: On the Coherence of Social Motivations. Personality and Social Psychology Review, 10, 88-110. https://doi.org/10.1207/s15327957pspr1002 1

Higgins, E. T. (1987). Self-Discrepancy: A Theory Relating Self and Affect. Psychological Review, 94, 319-340. https://doi.org/10.1037/0033-295X.94.3.319

Kim, P. H., Ployhart, R. E., \& Gibson, C. B. (2018). Editor's Comments: Is Organizational Behavior Overtheorized? Academy of Management Review, 43, 541-545. https://doi.org/10.5465/amr.2018.0233

Klepp, O. M., Mastekaasa, A., Sørensen, T., Sandanger, I., \& Kleiner, R. (2007). Structure Analysis of Antonovsky's Sense of Coherence from an Epidemiological Mental Health Survey with a Brief Nine-Item Sense of Coherence Scale. International Journal of Methods in Psychiatric Research, 16, 11-22. https://doi.org/10.1002/mpr.197

Larsson, G., \& Kallenberg, K. (1999). Dimensional Analysis of Sense of Coherence Using Structural Equation Modelling. European Journal of Personality, 13, 61-61.

Leindwan, P., \& Mainardi, C. (2010). The Coherence Premium. Harvard Business Review, $1-8$.

León, F. J. (2009). Workers' Logics. Study about Rationality, Autonomy and Coherence of Workers' Practices and Meanings. Revista Internacional de Sociología, 67, 135-160.

Lieberman, M. D. (2007). Social Cognitive Neuroscience: A Review of Core Processes. Annual Review of Psychology, 58, 259-289. https://doi.org/10.1146/annurev.psych.58.110405.085654

Maitlis, S., \& Christianson, M. (2014). Sensemaking in Organizations. Taking Stock and Moving Forward. The Academy of Management Annals, 8, 57-125. https://doi.org/10.5465/19416520.2014.873177

McCraty, R. (2011). Coherence: Bridging Personal, Social and Global Health. Activitas Nervosa Superior Rediviva, 53, 85-102.

McCraty, R., \& Childre, D. (2002). The Appreciative Heart: The Psychophysiology of Positive Emotions and Optimal Functioning. Boulder Creek, CA: HeartMath Research Center, Institute of HeartMath, Publication No. 02-026.

McCraty, R., Atkinson, M., Tomasino, D., \& Bradley, R. T. (2009). The Coherent Heart: Heart-Brain Interactions, Psychophysiological Coherence, and the Emergence of System-Wide Order. Integral Review, 5, 10-115.

Mercier, H. (2012). The Social Functions of Explicit Coherence Evaluation. Mind and Society, 11, 8192. https://doi.org/10.1007/s11299-011-0095-4

Morse, S., \& Gergen, K. J. (1970). Social Comparison, Self-Consistency, and the Concept of Self. Journal of Personality and Social Psychology, 16, 148-156. https://doi.org/10.1037/h0029862

Nadler, D. A. (2006). The Congruence Model of Change. In J. V. Gallos (Ed.), Organization Development. San Francisco, CA: Jossey Bass.

Olsson, E. J. (2014). Bayesian Epistemology. In S. O. Hansson, \& V. F. Hendricks (Eds.), Handbook of Formal Philosophy. Berlin: Springer.

Proulx, T., \& Inzlicht, M. (2012). The Five “A"s of Meaning Maintenance: Finding 
Meaning in the Theories of Sense-Making. Psychological Inquiry, 23, 317-335. https://doi.org/10.1080/1047840X.2012.702372

Proulx, T., Heine, S. J., \& Vohs, K. D. (2010). When Is the Unfamiliar the Uncanny? Meaning Affirmation after Exposure to Absurdist Literature, Humor, and Art. Personality and Social Psychology Bulletin, 36, 817-829.

https://doi.org/10.1177/0146167210369896

Ramos, V., \& Jordao, F. (2013). Are Public Workers More Stressed than Private Workers? The Relationship between Work Stress and Value Congruence. Psychology Research, 3, 396-408. https://doi.org/10.17265/2159-5542/2013.07.005

Randles, D., Inzlich, M., Prolux, T., Tullett, A. M., \& Heine, S. J. (2015). Is Dissonance Reduction a Special Case of Fluid Compensation? Evidence That Dissonant Cognitions Cause Compensatory Affirmation and Abstraction. Journal of Personality and Social Psychology, 108, 697-710. https://doi.org/10.1037/a0038933

Schubert, S., \& Olsson, E. J. (2012). On the Coherence of Higher-Order Beliefs. Southern Journal of Philosophy, 50, 112-135. https://doi.org/10.1111/j.2041-6962.2011.00089.x

Schubert, S., \& Olsson, E. J. (2013). Coherence and Reliability in Judicial Reasoning. In M. Araszkiewicz (Ed.), Coherence. Insights from Philosophy, Jurisprudence and Artificial Intelligence (pp. 33-58). Berlin: Springer. https://doi.org/10.1007/978-94-007-6110-0 2

Silvers, J. A., Weber, J., Wager T. D., \& Ochsner, K. N. (2015). Bad and Worse: Neural Systems Underlying Reappraisal of High- and Low-Intensity Negative Emotions. Social Cognitive Affect Neuroscience, 10, 172-179. https://doi.org/10.1093/scan/nsu043

Sperber, D. (2005). Modularity and Relevance: How Can a Massively Modular Mind Be Flexible and Context-Sensitive? In P. Carruthers, S. Laurence, \& S. Stich (Eds.), The Innate Mind: Structure and Contents. Oxford: Oxford University Press.

Swann, W. B. (1983). Self-Verification: Bringing Social Reality into Harmony with the Self. In J. Suls, \& A. G. Greenwald (Eds.), Social Psychological Perspectives on the Self (Vol. 2, pp. 33-66). New York: Lawrence Erlbaum Associates.

Swann, W. B., \& Read, S. J. (1981). Self-Verification Processes: How We Sustain Our Self-Conceptions. Journal of Experimental Social Psychology, 17, 351-372. https://doi.org/10.1016/0022-1031(81)90043-3

Swann, W. B., Griffin, J. J., Predmore, S. C., \& Gaines, B. (1987). The Cognitive-Affective Crossfire: When Self-Consistency Confronts Self-Enhancement. Journal of Personality and Social Psychology, 52, 881-889. https://doi.org/10.1037/0022-3514.52.5.881

Thagard, P. (2002). Coherence in Thought and Action (pp. 1-13). Cambridge, MA: MIT Press. http://books.google.com/books?id=Px0vctI8eGQC

Thagard, P. (2005). The Emotional Coherence of Religion. Journal of Cognition and Culture, 5, 58-74. https://doi.org/10.1163/1568537054068642

Toro, F. (2013). Organizational Climate. Intervention Based on Evidence. Medellin: Cincel. https://doi.org/10.21772/gco.ibe.c10

Toro, F. (2015). Reflection on Subjectivity and Coherence Judgments at Work. Revista Interamericana de Psicología Ocupacional, 34, 93-107.

https://doi.org/10.21772/ripo.v34n2a03

Toro, F. (2018). Coherence Judgments in Organizational Contexts. Contribution to a Theory of Coherence in Organizations. Doctoral Dissertation, San Juan: University of Puerto Rico.

Toro, F. (2019). Organizational Coherence: Experimental Evidence about Effects of Coherence Judgements. In VI Iberoamerican Congress of Organization and Work 
Psychology.

Von Hecker, U., Hahn, U., \& Rollings, J. (2016). Spatial Representation of Coherence. Journal of Experimental Psychology: General, 145, 853-871. https://doi.org/10.1037/xge0000176

Vygotsky, L. (1925). Consciousness as a Problem in the Psychology of Behavior. In Undiscovered Vygotsky: Etudes on the Pre-History of Cultural-Historical Psychology (European Studies in the History of Science and Ideas Vol. 8) (pp. 251-281). New York: Peter Lang Publishing.

http://www.marxists.org/archive/vygotsky/works/1925/consciousness.htm

Vygotsky, L. (1927). El sentido histórico de la crisis de la psicología. http://www.redalyc.org/articulo.oa?id=369139994065

Wagter, R., Proper, H. A., \& Witte, D. (2012). A Practice-Based Framework for Enterprise Coherence. In Practice-Driven Research on Enterprise Transformation (pp. 77-95). Berlin: Springer. http://link.springer.com/chapter/10.1007\%2F978-3-642-31134-5 4 https://doi.org/10.1007/978-3-642-31134-5 4

Weick, K. E., Sutcliffe, K. M., \& Obstfeld, D. (2005). Organizing and the Process of Sensemaking. Organization Science, 16, 409-421.

https://doi.org/10.1287/orsc.1050.0133

Zaki, J., Kallman, S., Wimmer, G. E., Ochsner, K., \& Shohamy, D. (2016). Social Cognition as Reinforcement Learning: Feedback Modulates Emotion Inference. Journal of Cognitive Neuroscience, 28, 1270-1282. https://doi.org/10.1162/jocn a 00978 